University of South Florida

DIGITAL COMMONS

Digital Commons @ University of

@ UNIVERSITY OF SOUTH FLORIDA

South Florida

9-8-2004

\title{
Moonlight in Miami: A Field Study of Human-Robot Interaction in the Context of an Urban Search and Rescue Disaster Response Training Exercise
}

Jennifer L. Burke

University of South Florida

Follow this and additional works at: https://digitalcommons.usf.edu/etd

Part of the American Studies Commons

\section{Scholar Commons Citation}

Burke, Jennifer L., "Moonlight in Miami: A Field Study of Human-Robot Interaction in the Context of an Urban Search and Rescue Disaster Response Training Exercise" (2004). USF Tampa Graduate Theses and Dissertations.

https://digitalcommons.usf.edu/etd/973

This Thesis is brought to you for free and open access by the USF Graduate Theses and Dissertations at Digital Commons @ University of South Florida. It has been accepted for inclusion in USF Tampa Graduate Theses and Dissertations by an authorized administrator of Digital Commons @ University of South Florida. For more information, please contact digitalcommons@usf.edu. 
Moonlight in Miami: A Field Study of Human-Robot Interaction in the Context of an Urban Search and Rescue Disaster Response Training Exercise

by

Jennifer L. Burke

A thesis submitted in partial fulfillment of the requirements for the degree of Master of Arts

Department of Psychology

College of Arts and Sciences

University of South Florida

Major Professor: Michael D. Coovert, Ph.D.

Robin R. Murphy, Ph.D.

Walter C. Borman, Ph.D.

Date of Approval:

September 8, 2003

Keywords: rescue robotics, communication analysis, field research methods, technology, user studies

(C) Copyright 2003, Jennifer L. Burke 


\section{DEDICATION}

To my parents Jane and Garfield for their faith in me and unwavering support, my daughter Sara for her inspiration and encouragement, and most of all my husband

Michael for his love, patience and understanding during the arduous journey of graduate study. 


\section{ACKNOWLEDGEMENTS}

This work was supported in part by DARPA under the Synergistic Cyber-Forces Seedling program (N66001-1074-411D) and the Cognitive Systems Exploratory Effort program (N66001-03-8921), and SAIC, Inc. The author would like to thank Jean Scholtz and Ron Brachman for their support. Many thanks to Jenn Casper, Mark Micire, and Brian Minten for their help in collecting the data, Thomas Fincannon for his assistance in editing and transcribing the videotapes, and Rescue Training Associates for providing the test venue. Michael Coovert provided expertise, encouragement and guidance as my advisor, and introduced me to Robin Murphy, who has served as role model and mentor throughout this process. I am grateful to both for the opportunities given and pathways opened. 


\section{TABLE OF CONTENTS}

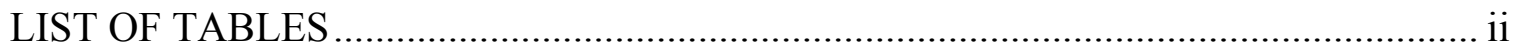

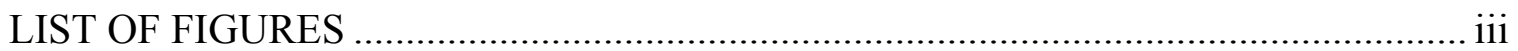

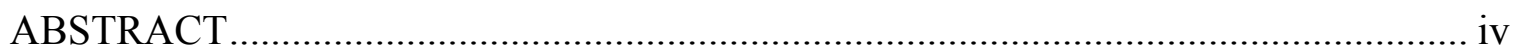

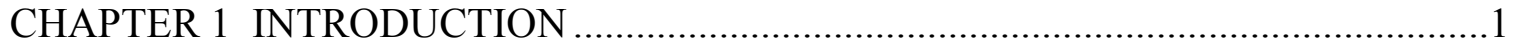

CHAPTER 2 OVERVIEW OF USAR AND TECHNICAL SEARCH ….......................5

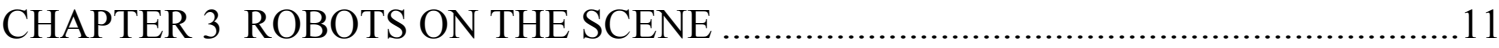

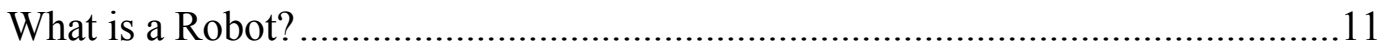

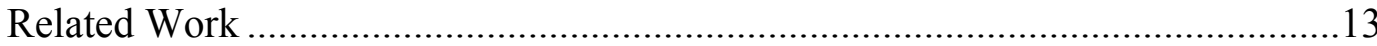

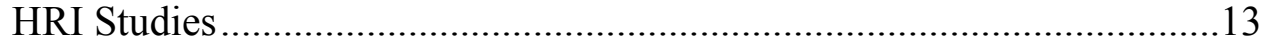

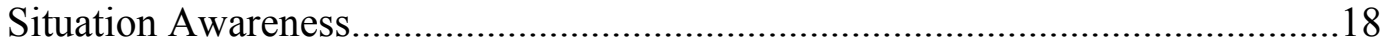

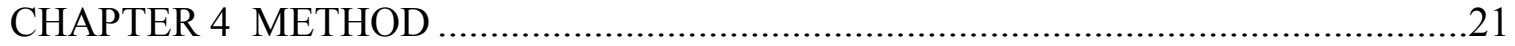

Participants, Apparatus, Setting and Procedure ..................................................21

Robot Assisted Search and Rescue Communication Coding Scheme ..................27

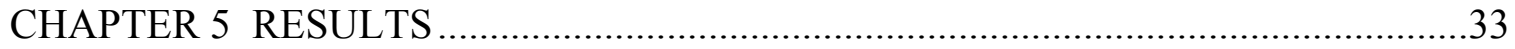

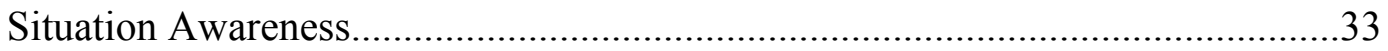

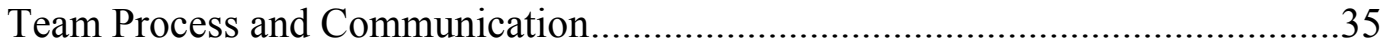

Interaction of SA and Team Communication ................................................40

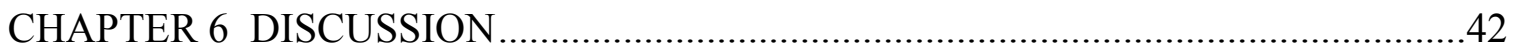

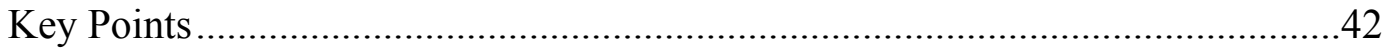

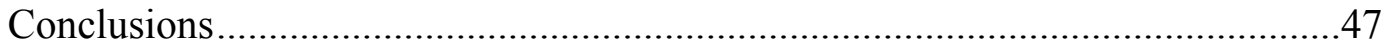

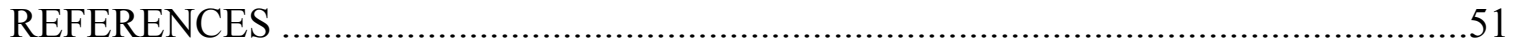

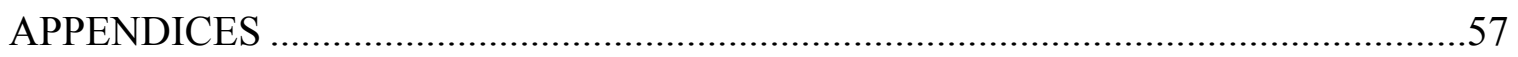

Appendix A Robot Assisted Search and Rescue Communication Coding $\begin{array}{ll}\text { Scheme (RASAR-CCS) } & 58\end{array}$

Appendix B Intercorrelations between operator statement categories ................61 


\section{LIST OF TABLES}

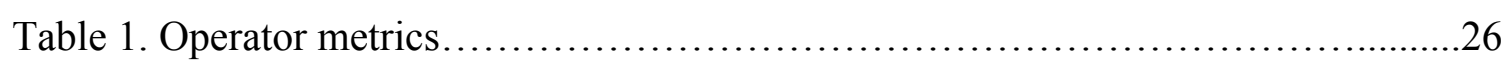

Table 2. Operator statement category frequencies and percentages..................36

Table 3. Dyad frequencies and percentages for tether managers and team members.......39

Table 4. Chi-square results for high and low SA operator statements................41 


\section{LIST OF FIGURES}

Figure 1. Organizational structure of USAR Task Force (FEMA, 1992)........................ 8

Figure 2. Inuktun Microtrax and VGTV robots...................................................... 23

Figure 3. Map of disaster response training site and robot run locations. ...................... 28

Figure 4. Percentages of operator statements by content........................................ 34

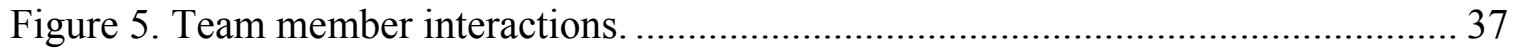


Moonlight in Miami: A Field Study of Human-Robot Interaction in the Context of an Urban Search and Rescue Disaster Response Training Exercise

Jennifer L. Burke

\begin{abstract}
This study explores human-robot interaction during a 16-hour high-fidelity Urban Search and Rescue (USAR) disaster response drill with teleoperated robots. Situation awareness and team interaction were examined using communication analysis. Operators $(n=5)$ sought assistance from team members to compensate for difficulties building or maintaining situation awareness. Operator-team member communication focused on relating what was seen through the robot's eye view with prior knowledge and planning search strategies. Results suggest operators need a new cognitive mental model to filter and comprehend data provided by the robot, and that robot-assisted search is a team task rather than an individual one. USAR technical search teams need a new shared mental model of robot-assisted search in order to coordinate activities effectively.
\end{abstract}




\section{CHAPTER I}

\section{INTRODUCTION}

Urban search and rescue (USAR) has been posed by the DARPA/NSF study on human-robot interaction (Murphy \& Rogers, 2001) as an exemplar domain for humanrobot interaction (HRI). USAR involves the rescue of victims from the collapse of a man-made structure. The environment can be characterized as a pile of steel, concrete, dust, and other rubble and debris. The areas are perceptually disorienting; they no longer look like recognizable structures due to the collapse, it is dark, and everything is covered in gray dust from concrete or sheet rock. Robot assisted search and rescue in this field domain, requires that small shoe-box sized physically situated robots operate under these unstructured, outdoor environmental conditions in real-time to visually search areas that are either too narrow for safe human or canine entry or generally unsafe for human exploration The robots are short, providing a viewpoint from less than one foot off the ground. This exacerbates any "keyhole effects" (Woods, Tittle, Feil \& Roesler, in press). These domain and agent characteristics present many challenges that distinguish USAR from other HRI settings, e.g. manufacturing, entertainment and office-oriented applications.

The relationship between humans and robots in USAR is different than manufacturing, office, or even security applications of robots. Possibly the most interesting HRI aspect is that robots, much like search dogs, must physically team with people to perform any activity. Because of their small size and the mobility challenges 
imposed by the USAR environment, robots must be carried in backpacks to the voids targeted to be searched. Second, humans must interpret the video, audio, and thermal imaging data provided from the robots and fuse it with other data sources (e.g., building plans) and knowledge (e.g., time of day) in order to identify victims and structural anomalies as well as conduct and coordinate large-scale rescue efforts. The information extracted from the robot's search must be abstracted and propagated up a hierarchy of decision makers as well as distributed laterally among search specialists. Therefore, the human-robot team must cooperatively transform data into information and levels of knowledge. This means HRI in USAR must consider distributed information transfer and cooperation. Third, the operators and decision-makers (consumers of information provided by the robots) are under extreme cognitive and physical fatigue, introducing new issues not commonly seen in industrial settings. Any progress in HRI for USAR applications would likely be applicable to military and security applications, which are also time-critical, high-stress domains. Fourth, the high degree of human involvement is not expected to change in the near future. The robots are not autonomously mobile for the demanding conditions of a rubble pile, and the most optimistic roadmap posits only navigational autonomy within 10 years (Murphy, 2002.) As a result robots require at least one operator, and often a robot will need a second operator to manipulate a tether or safety line for lowering into vertical voids. This introduces the possibility of a more diverse team, with humans serving multiple roles in controlling one robot. Fifth, USAR is a domain where the robots perform tasks that cannot be accomplished by a living creature; thus the operator has no higher metaphor or example of how to use the robot. 
By studying human interactions with USAR robots, it may be possible to learn how to accelerate the generation of new strategies for deploying robots.

This study investigates human-robot interaction during robot-assisted search and rescue activities observed as part of a high-fidelity USAR field training drill in Miami, Florida, managed by Rescue Training Associates. The 16-hour drill was conducted on November 30, 2001, in collapsed buildings and rubbles piles, creating a realistic physical setting. It was the "final exam" for two days of classes in urban search and rescue for 75 firefighters and USAR workers. The Center for Robot-Assisted Search and Rescue (CRASAR) was permitted to tape how the robots were used by the students and instructors during the drill in exchange for providing a short classroom training session on how the robots were used for visual technical search at the World Trade Center response (Casper and Murphy, 2003; Casper, 2002; Micire, 2002). It should be emphasized that data collection was opportunistic and observational: the drill was not structured for a formal HRI study and there were no hypotheses generated before hand. The conditions of the drill (most night-time, exposed rubble and rebar) made roving videotaping particularly unsafe, and only stationary activities (the operator at the control station after it was set up) could be recorded without risking injury. Although data collection was conducted without a particular hypothesis, the analyses reported in this article focus on situation awareness (SA), and team process and communication. Previous work suggests SA and teamwork are needed for effective task performance in complex, high stress work domains similar to USAR (Prince \& Salas, 2000; Stout, Cannon-Bowers, Salas \& Milanovich, 1999; Sonnenwald \& Pierce, 2000) and HRI 
studies of USAR (Casper \& Murphy, 2003; Casper \& Murphy, 2002) support the need for SA. By establishing indicators of situational awareness in robot assisted search and rescue, the study serves as a foundation for creating the appropriate cognitive augmentation needed for effective technical search. The findings concerning human-torobot ratios have profound ramifications not only for USAR operations, but also for other robotic domains. In addition, investigation of the rescue teams' communication as they work with the robots may provide insight into the development of both individual and shared mental models of the robot, the environment and the search task needed for robotassisted search operations

The rest of this study is organized as follows. Chapter 2 provides an overview of the USAR domain and the activities in technical search task. Chapter 3 provides an overview of robotics and a summary of related HRI work in observational field studies, and defines situation awareness for the purposes of this study. Chapter 4 details the methodology used for the observational study, coding of the video data, and analyses. Results, including patterns of team communication and indicators of situation awareness are presented in Chapter 5. Chapter 6 discusses the implications and questions raised by the findings, and notes the need for cognitive augmentation to improve human performance. 


\section{CHAPTER 2}

\section{OVERVIEW OF USAR AND TECHNICAL SEARCH}

The organizational structure of USAR poses interesting challenges for effective human-robot interaction. This section summarizes salient points about the technical search task and the use of robots; the reader is directed to Casper (2002) for a more indepth description of USAR from a HRI viewpoint. It is important to note that rescue robots are not used by traditional response teams; instead the Center for Robot-Assisted Search and Rescue (CRASAR) maintains an independent team which deploys with national or international teams. The intent is to integrate mature robot technologies into the standard team cache. The description below represents the deployment strategy recommended by the CRASAR response team at the time of the Miami drill. Technical search is one of many emergency response tasks. In the USA, operations at a mass-casualty incident are divided into twelve emergency support functions (ESF), ranging from medical support (organizing hospitals and ambulances) through logistics (making sure that food and portable toilets are available to workers). Each ESF is conducted by a specially trained task force and coordinated through an incident commander and the incident command staff. USAR is only one function, designated ESF 9, within the larger incident organization. Technical search is one task within USAR.

Personnel who conduct technical search are highly trained members of a cohesive team and generally work in pairs (the "buddy system") for safety. USAR functions and personnel require advanced training and equipment; as a result it is generally conducted 
by a designated federal or state task force. There are currently 28 federal task forces recognized by the Federal Emergency Management Agency and possibly up to four times as many teams responsible for highly populated urban areas of states. Both federal and regional teams typically share the same organization, fielding a 56-person Task Force in order to sustaining operations around the clock (in 12-hour shifts) for a maximum of 10 consecutive days. The teams are composed of a) firefighters, paramedics and Emergency Medical Technicians and b) civilians, most often in canine search, structures, and hazardous materials. USAR workers routinely log over 200 hours of USAR-specific training each year. Most firefighters have not had four years of college, while most civilians have. Task forces are usually elite and highly cohesive, where the members are hand-picked for both skills and social dynamics.

USAR operations are physically and cognitively fatiguing. Every member who works in the hot zone (collapse site) must be able to physically negotiate rubble piles and uneven surfaces, work in confined spaces, climb ladders and work at heights, and quickly exit void spaces to avoid secondary collapses. Task force members wear specialized safety equipment, and are closely monitored for signs of physical exhaustion or stress (particularly Critical Incident Stress Syndrome) when working. Although the teams work in 12-hour shifts, the reality of both shifts setting up operations and infrastructure and working in the field during the first 24 hours leads to sleep deprivation. It is conventional wisdom that a responder will get less than 3 hours of continuous sleep during the first 48 hours of an incident. The sleep deficit does not decrease during the 10 day deployment. 
Technical search, as seen in Figure 1, is one of the four USAR functions: search, technical support, medical, and rescue or extrication. These four operations represent sub-specialties within the task force. While no two disasters are managed precisely the same way, USAR operations often begin with a manual reconnaissance of the area of damage, called the hot zone. Victims on the surface or easily removed from light rubble are extracted immediately as encountered. After reconnaissance, the command staff determines what the safest strategy is to effectively search the hot zone for survivors within the rubble. In areas that are deemed safe for humans to investigate, canine teams may be sent forward. 


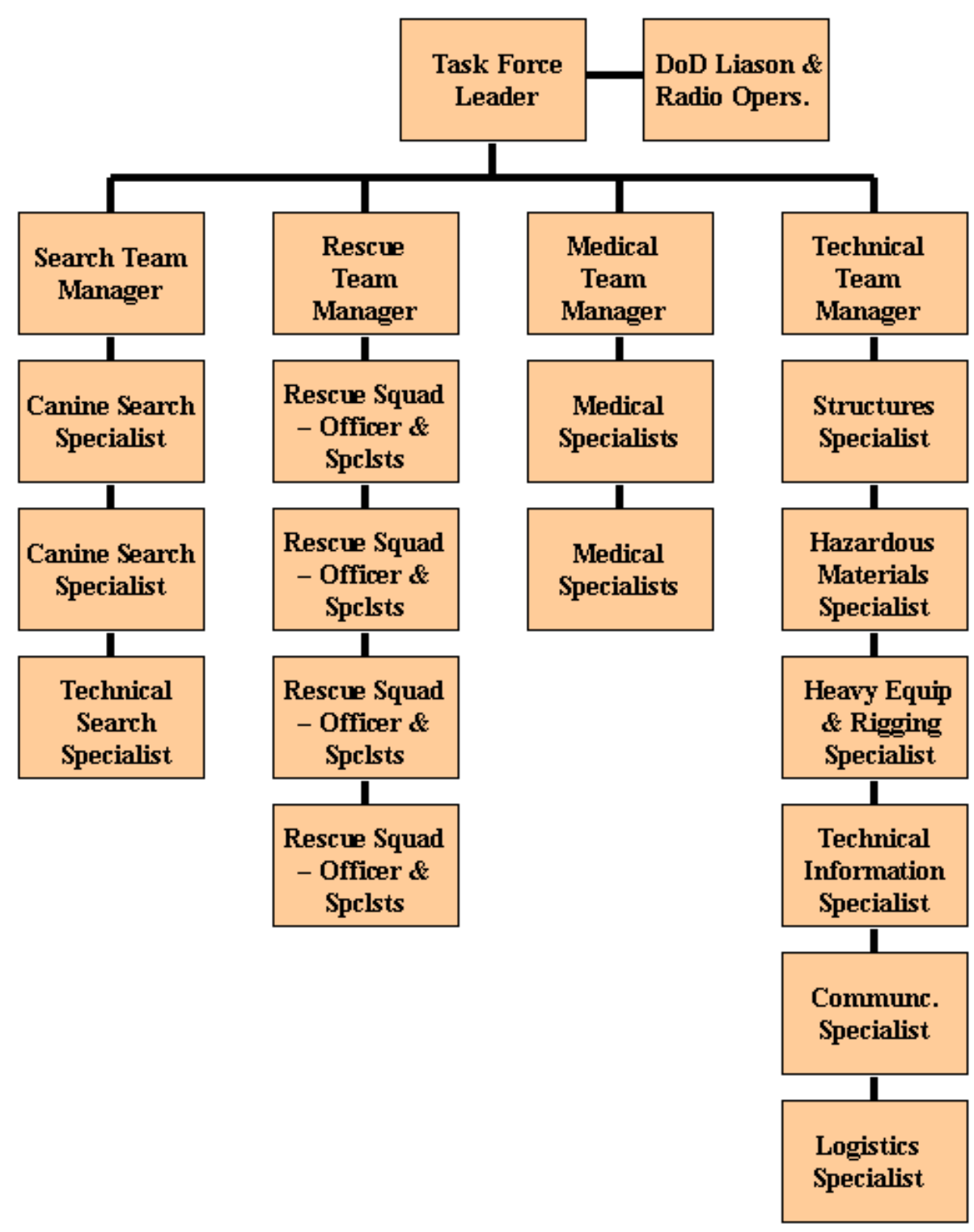

Figure 1. Organizational structure of USAR Task Force (FEMA, 1992).

In most cases, technical search specialists wait until called for. When a dog has indicated signs of a survivor in an area, technical search specialists are summoned onto 
the pile. The command staff attempts to minimize the number of people in the hot zone, so technical search specialists wait at the "forward station" of the hot zone perimeter until called over the radio or assigned an area to search. A technical search specialist may carry a fiber-optic boroscope, thermal imager, or a video camera mounted on a wand for a visual inspection of the rubble, depending on the verbal description of the void or the specific request of a particular device by the leader. If a survivor is found, the search team and command staff brings in the medical and rescue teams, who call on members of the technical support team as needed. Before leaving the void, the technical search specialists mark the exterior of the void with symbols indicating that it has been searched, the structural condition, and presence of survivors/remains.

The visual inspection of a void is most often done with a boroscope or a camera on a wand. These technologies generally cannot penetrate more than 12 feet into a void, whereas robots are well-suited for voids longer than 20 feet. Regardless of tool, the search activity takes on the order of 3-30 minutes, and a technical search specialist may spend most of a 12-hour shift waiting, and then work furiously for a few minutes. The command staff may periodically evacuate the hot zone and cease all operations so that technical search specialists can apply sensitive acoustic listening devices. This also adds to the cognitive stress. No evacuations were called for during the Miami drill while the robots were deployed.

The field data collected in the Miami drill used the robots for a visual technical search task, where robots served as "cameras on wheels." The visual technical search task consists of four activities in order of importance: search for signs of victims, report of 
findings to the team or task force leader, note any relevant structural information that might impact the further investigation of the void, and estimate the volume that has been searched and map it relative to the rubble pile. In this case, the technical search specialist operated a robot instead of a boroscope or thermal imager. It should be noted that the team leader is responsible for integrating the information about maps, safety risks, location of victims, and coverage of the pile. Thus, technical search task is highly focused and generally limited to a short period of time where the searcher is called onto the pile, carries the technical equipment to the site, sets it up, gets results, and then returns to the forward station. The data collected during the drill attempted to capture how the operator was searching for signs of survivors and noting structural information, since these were the activities with direct human-robot interaction. 


\section{CHAPTER 3}

\section{ROBOTS ON THE SCENE}

\section{What is a Robot?}

The term robot came from Karl Capek’s 1921 play R.U. R. (Rossum's Universal Robots). It was used to describe a race of menial workers, "artificial humans" created from a vat of biological parts to serve as slave labor for real humans. Science fiction books and movies transformed robots into mechanical creatures, and propitiated their menial stance by portraying them as factual-minded automatons that mimicked human qualities without understanding.

In reality, an intelligent robot is a mechanical creature which can function autonomously and interact with its world (Murphy, 2000). Intelligence implies it does not perform in a mindless fashion, while autonomy means it can adapt to changes in the environment (or itself) and continue to reach its goal. Brooks (2002) defines two principles that distinguish robots from computers: situatedness and embodiment. Robots are situated in that they are embedded in the world, and interact with the world through sensors which influence their behavior. They are embodied in that sense of having a physical body that experiences the world in part through the influence of the world on that body. Like computers, robots have evolved from research laboratories and military/industrial applications, and are rapidly gaining a presence in the worlds of entertainment, work and everyday life. 
Robots have traditionally been used for the three D's: dull, dangerous or dirty work. Industrial robots have been developed for economic reasons in manufacturing, agriculture and service industries, to increase productivity and reduce inefficient human resource allocation, particularly in hard-to-staff menial labor positions. Because the original goal was precision and repeatability for use in mass production, little effort was put into machine intelligence or human factors considerations. As the space program evolved, the need for artificial intelligence, i.e. robots capable of learning, planning, reasoning and problem-solving, spurred research sponsored not only through NASA, but also by the Defense Advanced Research Projects Agency (DARPA). Mobile robots have developed more from safety and humanitarian concerns, and are the primary focus in nuclear, space exploration, military and rescue applications. This study is directed toward human-robot interaction with mobile robots. While the pervading notion in past research has been the substitution of robots for people, the current trend is toward robots as assistive technology, i.e. designed to complement humans rather than replace them.

The current state of the art in mobile robots is situated autonomy (the robot acts on its own using information from its sensors), though teleoperation is more common in practice. Teleoperation is when a human operator controls a robot from a distance using sensors and a display. (This differs from remote-control operation, where the operator has visual contact with the robot). Some applications have moved to semi-autonomous control, where the robot is given an instruction or task to do on its own (but under supervision). Others have built upon the notion of shared control, where the robot does the dirty work and the human does that which requires finesse. Certainly there are more 
autonomous applications in the commercial sector (Honda's Asimo, Sony's Aibo robotic dog), but systemic problems have slowed the rate of development in military and governmental application.

Related Work

Human-robot interaction is a relatively new field. For an overview, the reader is referred to the DARPA/NSF study on human-robot interaction (Murphy \& Rogers, 2001). Our study differs from existing research in HRI in three dimensions: goals, methodology, and focus. Of the relatively small number of studies in HRI, only three studies address HRI in field domains, one using data from a USAR exercise in July 2001, one using data from the WTC, and the third with SWAT teams. Situation awareness emerged as a common theme across the three studies, and shared mental models of the problem space were a critical factor in the SWAT team study. Endsley's three-level model of situation awareness (1988) is used in analysis of the data collected, and is briefly reviewed.

\section{HRI Studies}

Human-robot interaction is significantly different from human-computer interaction in several ways (Scholtz, 2003.) Robots are embodied and can move and interact with humans in dynamic, real-world environments. Their platforms hold sensors that can fail or degrade. Users may interact with more than one independent system, and systems may have varying degrees of autonomy and cognition. These dimensions pose 
challenges for designers of human-robot systems, and those who seek to best utilize the rich potential of complementary relationships between the two.

Human-robot interaction, in turn, is a relatively new field, and this study differs from existing research in HRI in three dimensions: goals, methodology and focus. Most studies have addressed social acceptance of robots or interface design (Breazeal, 2000; Arkin, R., Fujita, M., Takagi, T., and Hasegawa, R., 2003; Draper, Pin, Rowe \& Jansen, 1999; Wilkes, Alford, Cambron, Rogers, Peters \& Kawamura, 1999; Khatib, Yokoi, Brock, Chang \& Casal, 1999; Thrun, 1998; Nicolescu \& Mataric, 2001.) In contrast, this study examines direct relationships between humans and robots performing tasks in work contexts. Experiments in laboratory or other controlled settings, simulations and modeling techniques are the most common methods of HRI study, with few studies conducted in the field (Breazeal, 2003; Kiesler \& Goetz, 2002; Kawamura, Nilas, Muguruma, Adams \& Zhou, 2003; Severinson-Eklundh, Green \& Huttenrauch, 2003; Langle \& Worn, 2001; Nakamura, Ota \& Arai, 2002; Fong, Thorpe \& Baur, 2001.) . This study is an observational field study of users working with robots in real environments. Current theoretical models and taxonomies of human-robot interaction focus on levels of autonomy-existing or hypothesized- for known human tasks (Murphy \& Rogers, 2001; Scholtz, 2003; Woods et al., in press.) This study is concerned with identifying new tasks for robots in the search and rescue domain, with robots that are, for the present, teleoperated.

There is some research that is similar to the current study, i.e. applies to robots and humans in field work settings, rather than office, web, or manufacturing-type 
scenarios: current work in the USAR domain (Casper, 2002; Casper \& Murphy, 2002; Micire, 2002), a field study of SWAT teams (Jones \& Hinds, 2002), NASA's Robonaut research (Bleuthmann et al., 2003) and Kraut, Fussell \& Siegel's (2003) related remote collaboration study.

Existing research in robot-assisted USAR from pre-9/11 field trials and the first known deployment of robots in a disaster response (Casper, 2002; Casper \& Murphy, 2002) revealed difficulties in operator teleproprioception and telekinesthesis, as described in Sheridan (1992.) Prior to the World Trade Center disaster, one ethnographic study conducted (Casper \& Murphy, 2002) documented workflow patterns in field trials with rescue workers and two types of tactical mobile robots. The study identified collaborative teleoperation, i.e., two operators with two robots assisting one another, as a team-based work strategy for efficient navigation and error avoidance. While formal ethnographic methods were not used to study robot-assisted operations at the WTC, video data was collected and analyzed post 9/11 in Casper (2002) and Micire (2002). Important findings emerged regarding the environment, tasks, communication and logistics requirements, and social informatics (Casper, 2002). The high stress environment present on-site quickly revealed the need to address cognitive deficits brought on by fatigue and lack of sleep, both ever-present conditions in USAR operations. Issues such as packability of the robots and complexity of the interfaces influenced rescue workers' willingness to use the robots in technical search tasks. Acceptance of the robots also appeared to be related to workers' prior experience with other technical search tools. Robot failures due to traction slippage, camera occlusion and lighting adjustments retarded the search process. Findings 
suggested that tether management, the lack of image processing, and difficulties in size and depth estimation must be addressed in order to aid fast and accurate victim detection (Micire, 2002.) Finally, robot information is a one-to-many mapping with temporal and abstraction hierarchies. The timely and appropriate distribution of information is critical to effective use of rescue robotics.

In a domain very similar to USAR, Jones and Hinds (2002) observed police SWAT teams in training exercises, and identified leader roles in establishing common ground and coordinating distributed team member actions as factors transferable to system design for coordinating distributed robots. Like search and rescue teams, SWAT teams operate in high stress, time-critical work environments. In this qualitative field study, researchers observed leaders' roles and actions in four field exercises as they coordinated and directed distributed SWAT teams. Leaders formed global mental models to build common ground (shared situation awareness) among distributed team members. They found SWAT teams use objects and spatial relations to coordinate actions, and that sharing common ground from the recipient's perspective increased situation awareness and team performance. These findings were incorporated into a system design using an object-centered electronic dialogue between an operator and multiple, distributed robots. A Correspondence Agent was created to assist the operator in building global SA, and to send commands to distributed robots using their own frame of reference.

This field study of team-based USAR operations differs from Jones and Hinds' work in that I am observing real robot-user interaction as it occurs between operator(s) and a single robot to inform present, not future, coordinated human-robot systems. Their 
findings regarding the criticality of shared awareness in team-based, dynamic work domains, however, are certainly applicable.

Though studied through simulation rather than functional application, NASA's Robonaut research platform (Bluethmann et al., 2003) shares some commonality with USAR HRI, as well, in that the focus is on the operator-robot relationship in a work context. Robonaut is designed to work in close proximity to humans, performing existing human tasks with existing tools, however, while robots in rescue operations go in places humans cannot (or should not) go, and perform tasks that are yet to be fully defined.

The remote collaborative physical task studies reported in Kraut, Fussell \& Siegel (2003) are not robot-related; however, there are important aspects that are relevant to human-robot interaction in search and rescue operations, namely, the contribution of shared visual space to situation awareness. In two experiments examining the effects of visual information on a collaborative repair task, the researchers used conversation analysis to compare differences between expert assistance given side-by-side, remotely using shared visual space, and remotely through audial channels only. Researchers observed a worker wearing a head-mounted video system that provided a remote helper with a view of what the worker was looking at during a collaborative bicycle repair task. Findings were that side-by-side assistance was more effective than remote assistance augmented with shared visual information, due to the limitations in shared visual space, the lack of spatial orientation and other physical-perceptual cues, and the consequent need to spend more time establishing common ground. Remote visual assistance was more effective than audial-only assistance, however, emphasizing the increased situation 
awareness made possible through the visual information that was shared. Conversation analysis results showed the advantage of shared visual space in establishing common ground (shared situation awareness) between the worker and the remote helper. Recommendations included suggestions for video configurations for remote collaboration.

The findings from these studies all point to situation awareness, perception and communication during tasks as critical aspects of human-robot interaction. Operators in field tests and at the WTC did not know how to interpret what they saw through the robot's camera, partly because of fatigue, and partly because of the lack of expected perceptual cues (Casper, 2002; Casper \& Murphy, 2002.) Like the remote helper in the distributed collaborative task, what they saw did not match their internal mental model. While no formal hypotheses are posed, I anticipate these will be salient factors in USAR robotics.

\section{Situation Awareness}

The exploration of SA in robot-assisted search operations in Chapter 5 is based upon Endsley's three-level model, which defines situation awareness as “...the perception of the elements in the environment within a volume of time and space, the comprehension of their meaning and the projection of their status in the near future (1988, p.97) (italics added). Perception (Level 1 SA) is detection of sensory information: the perception of elements in the environment within a volume of time and space. 
Comprehension (Level $2 \mathrm{SA}$ ) is divided into two subcategories, identification and interpretation. Identification is defined as comprehension of perceived cues in terms of subjective meaning: e.g., identifying objects, locations and victims. Interpretation is defined as comprehension of perceived cues in terms of objective significance or importance to the current situation. Projection (Level $3 \mathrm{SA}$ ) is defined as the projection of future situation events and dynamics through projecting, generating and activating solutions/plans.

Endsley's model is based on an information-processing theory (Wickens, 1992), in which SA is acquired largely through sensory input: sight, sound, touch, taste and smell. Perception and attention are important elements in taking sensory data into working memory, where it is coded and pattern-matched with existing goals and mental models in long-term memory. Jones \& Endsley (1996) noted that $76 \%$ of SA errors in pilots were due to problems in perception. This is of particular interest to this study, where the impact of perception on the control of robots is expected to be similar.

SA also comes from many other sources in addition to sensory input, e.g. system knowledge, prior knowledge, and from other people in the environment. Mental models play an important role in dealing with the limitations of working memory. Operators develop internal representations of the technology they use and the environment in which they use it. These mental models help direct limited attention efficiently, integrate information and provide a way of projecting future events or states. As Endsley (2000) states, "The use of mental models in achieving SA is considered to be dependent on the ability of the individual to pattern match between critical cues in the environment and 
elements in the mental model"(p.16.) Mental models support SA; they can also hinder it if the mental models are inaccurate. In the Jones \& Endsley study referenced earlier, 20\% of SA errors were associated with problems with mental models (1996.)

Research on teams and mental models has suggested that having a shared mental model of the problem space can increase SA and team performance (Stout, CannonBowers, Salas \& Milanovich, 1999; Sonnenwald \& Pierce, 2000.) Effective planning and communication strategies were found to increase team shared mental models and correspondingly team performance. In a study of military command and control exercises, Sonnenwald \& Pierce (2000) found frequent communications between team members about the work context and situation, work process and domain-specific information were needed to maintain shared situation awareness in dynamic, constraintbound contexts. 


\section{CHAPTER 4}

\section{METHOD}

This chapter describes the participants, apparatus and setting of the field study, the Robot-Assisted Search and Rescue Communication Coding System (RASAR-CSS), and the method of analysis used to interpret the data. Five operators were videotaped operating one of three Inuktun robots in a 16-hour disaster response drill. A description of the drill site, the training conducted prior to the drill, and timeline of the exercise are presented. Statements made by or to the operators were coded by two independent raters into categories generated by a content analysis of the operator statements. Reliability analyses conducted showed acceptable ranges of Cohen's kappas for interrater reliability. Following the coding of each operator, raters through consensus assigned a global rating of situation awareness using a 5-point Likert scale. Correlational and chi-squared analyses were conducted based on the data collected.

Participants, Apparatus, Setting and Procedure

The five participants in the study were three student participants of the disaster response training exercise and two instructors. Though demographic information for the five study participants was not available, they were a subset of the approximately 75 students and approximately 15 instructors involved in the drill, who can be characterized as a) current USAR Task Force members serving as instructors or completing required 
recertification training hours; or b) first responders (firefighters and emergency medical technicians) seeking USAR certification in order to be eligible to serve on a regional Task Force team. The majority of students had no urban search and rescue experience for a weapon of mass destruction event or natural disaster (e.g., collapse of a large building due to an explosion or earthquake).

The apparatus used in the study consisted of three robotic systems: two Inuktun Microtracs System robots and an Inuktun MicroVGTV robot (see Figure 2). The user interface offers little information beyond a visual view of the environment from the robot's camera. Scale, dimensionality and color resolution are known constraints. The three robots are small, tracked platforms equipped with a color CCD camera on a tilt unit and two-way audio through a set of microphones and speakers on the robot and operator control unit. The VGTV (Variable Geometry Tracked Vehicle) is a polymorphic robot which can change from a flat position to a raised, triangular position. Its design allows the vehicle to change shape while moving to meet terrain and obstacle challenges, and it is capable of lifting the camera up to a higher vantage point (about 10.5 inches high when raised to maximum height). All three robots are powered and controlled through a 100foot tether cord that connects the operator control unit (OCU) and the robot. The Inuktun robots have limited communication capability. The operator is given basic control capability: traversal, power, camera tilt, focus, illumination, and height change for the VGTV.

The setting for this study was a 3-day disaster response training exercise offered by Rescue Training Associates, Inc. in Miami, FL on November 28-30, 2001. The exercise 
consisted of 2 days of intensive hands-on training which included collapse shoring, concrete breaching \& breaking, heavy metal cutting and crane operations, technical search operations and WMD/HazMat operations followed by a 16-hour deployment drill on an actual collapse site. As part of the Technical Search Operations module, which exposes course participants to the latest technical search innovations, all students received 20 minutes of awareness-level instruction in rescue robotics conducted by researchers from USF's Center for Robot-Assisted Search and Rescue.
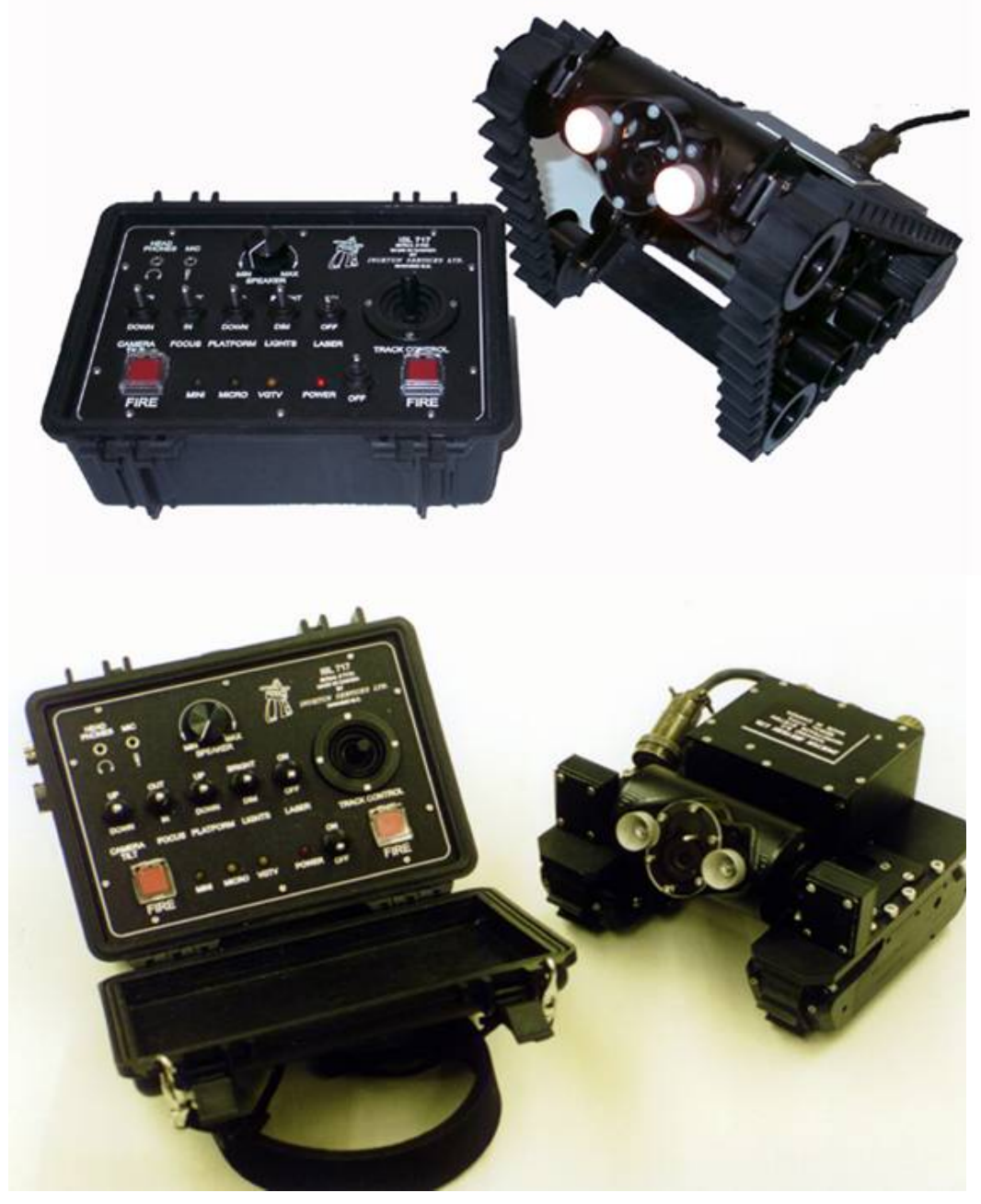

Figure 2. Inuktun Microtrax and VGTV robots. 
The awareness training course was designed to provide the students with a mental model of how the robot worked, and to provide an opportunity for hands-on experience teleoperating a robot (though time constraints precluded all students from having the chance to do so). The course did not cover any strategies for deployment, because CRASAR had not identified and codified any strategies at that time.

For the 16-hour high fidelity response drill, a 2-story warehouse in a light industrial park near the airport was partially collapsed, creating a large rubble pile. In addition to the collapsed building, two large rubble piles and an abandoned automobile that was set on fire were used for training operations. Figure 3 shows the layout of the collapse site and debris and rubble piles. The site was not simplified and significant safety hazards were present. Large chunks of concrete walls, tangled rebar, and loose electrical wiring posed the main hazards to people on the piles. Weather and visibility conditions are not always conducive to rescue operations, but in this case the night was clear (almost full moon) and the temperature normal for the area (@705).

The drill was attractive because it duplicated a real incident in terms of physical setting and in how the response was conducted. At the start of the drill, participants were checked in, divided into three teams, assigned roles and transported to the site. Once at the site, they established scene security, set up the Base of Operations, and conducted site safety and operational surveys. Field operations commenced at 10:30 P.M., approximately 4 hours after the drill began. During field operations, the robot cache was available for deployment on call. Robots were deployed in three areas of the hot zone, as shown in Figure 3. When a team requested a robot via radio, two or three researchers 
would move to the requested location and set up the robot for use, explaining the controls to the operator as needed. A student or researcher was designated as tether manager for the operator, i.e. uncoiled and recoiled the tether cord, and sometimes shook or popped the cord to free it from debris.

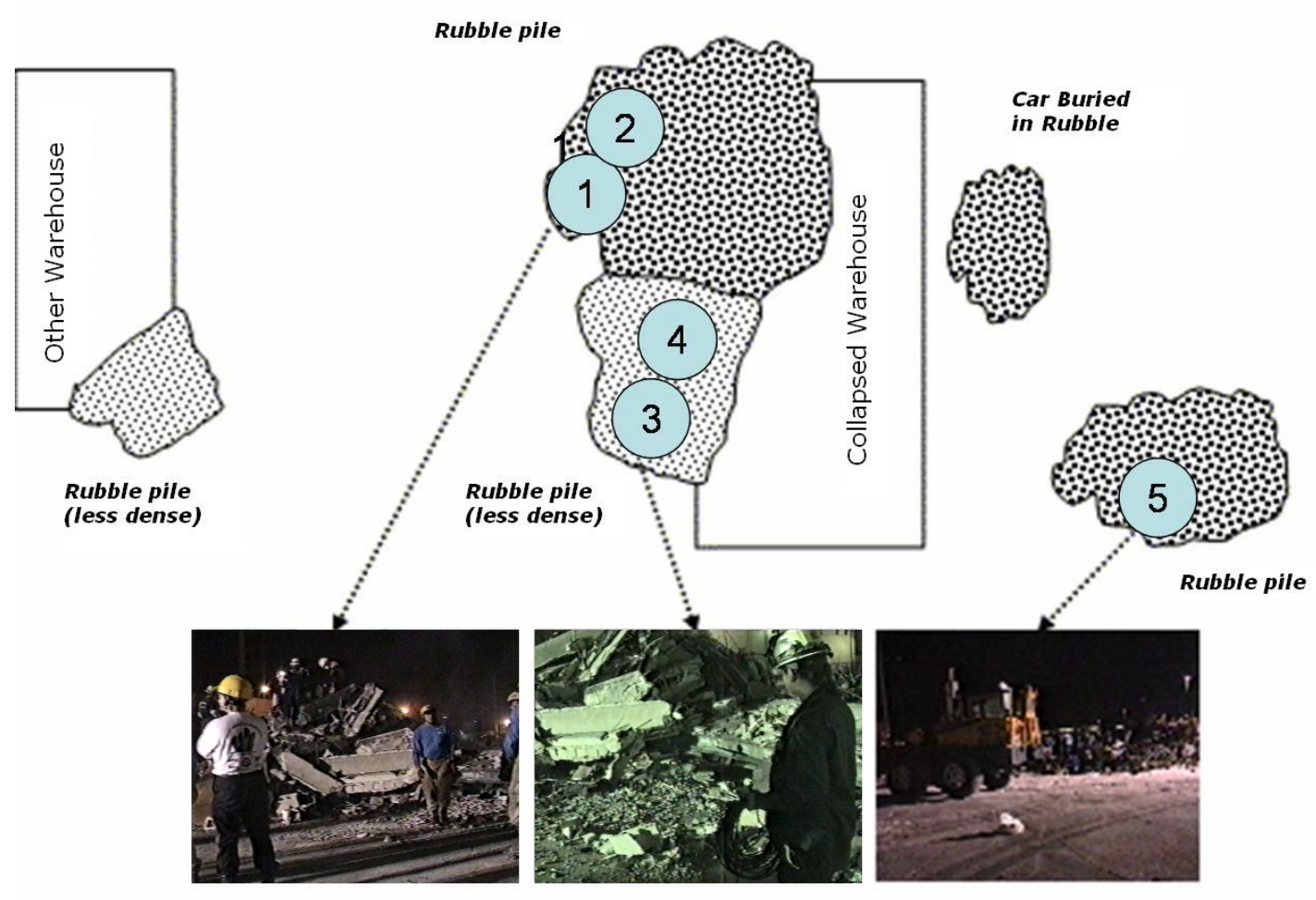

Figure 3. Map of disaster response training site and robot run locations.

The data collection process was a modified version of the procedure used by Casper (2002.) Two cameras simultaneously recorded 1) the view through the robot's camera (what it sees) and 2) a view of the operator and the Operator Control Unit (what the operator is seeing and doing.) When the robot was visible, a third video unit recorded an external view of the robot in use. 
The robot was deployed five times (see Table 1). Three of the five runs (runs 1, 2 and 5) were initiated on request by the teams. The first two runs searched the main rubble pile located next to the collapsed building. The fifth run used the robot during victim recovery operations on the smaller rubble pile in an attempt to get a visual of or pathway to the victim. The other two runs (runs 3 and 4) were initiated by instructors to gain hands-on experience with the robots. In these runs, areas that had already been searched by the teams were explored. In each run, members of the team self-organized to run the robot, with runs 2, 4 and 5 involving 2 members of the team. In runs 1 and 3, an additional participant became spontaneously involved by looking over the shoulder of the operator and interacting. The remainder of the team was either occupied with other tasks or passively observed. The five runs yielded a total of $66 \mathrm{~min} 16 \mathrm{sec}$ of videotape for analysis.

Table 1. Operator metrics.

\begin{tabular}{lllllll}
$\begin{array}{l}\text { Operator } \\
\#\end{array}$ & $\begin{array}{l}\text { Start Time } \\
\text { (approximate) }\end{array}$ & $\begin{array}{l}\text { Duration } \\
\text { (min- } \\
\text { sec) }\end{array}$ & $\begin{array}{l}\text { Robot } \\
\text { Used }\end{array}$ & $\begin{array}{l}\text { H-R } \\
\text { Ratio }\end{array}$ & $\begin{array}{l}\text { Total \# Operator } \\
\text { Statements }\end{array}$ & $\begin{array}{l}\text { Statements: } \\
\text { Minute Ratio }\end{array}$ \\
\hline $1(\mathrm{~S})$ & 10:45 P.M. & $14: 20$ & VGTV & $3: 1$ & 82 & $5.73: 1$ \\
2(S) & $11: 25$ P.M. & $13: 48$ & VGTV & $2: 1$ & 66 & $4.78: 1$ \\
$3(\mathrm{I})$ & 12:45 P.M. & $14: 39$ & VGTV & $3: 1$ & 54 & $3.68: 1$ \\
$4(\mathrm{I})$ & 1:05 A.M. & $14: 52$ & VGTV & $2: 1$ & 60 & $4.03: 1$ \\
$5(\mathrm{~S})$ & 3:15 A.M. & $3: 42$ & MicroTrax & $2: 1$ & 10 & $2.70: 1$ \\
\hline & & $\mathrm{M}=12: 16$ & & & $\mathrm{M}=54$ & $\mathrm{M}=4.4: 1$ \\
& & $\mathrm{SD}=4: 48$ & & & $\mathrm{SD}=24$ & $\mathrm{SD}=1.17: 1$ \\
\hline
\end{tabular}

$(\mathrm{S})=$ student

$(I)=$ instructor 
Robot Assisted Search and Rescue Communication Coding Scheme

Since Robot Assisted Search and Rescue is a relatively new field, there are no existing domain-relevant methods of analysis (e.g. communication coding schemes). The FAA's Controller-to-Controller Communication and Coordination Taxonomy $\left(\mathrm{C}^{4} \mathrm{~T}\right.$; Peterson, Bailey, \& Willems, 2001) uses verbal information to assess team member interaction from communication exchanges in an air traffic control environment. The $\mathrm{C}^{4} \mathrm{~T}$ is applicable to this work in that it captures the "how" and "what" of team communication by coding form, content and mode of communication. The goal, however, is two-fold, not only to capture the "how" and "what" of USAR robot operator teams, but also the "who", and to capture observable indicators of robot operator situational awareness. Therefore I developed a new coding scheme, the Robot Assisted Search and Rescue Communication Coding Scheme (RASAR-CCS). Although the development of the RASAR-CCS is guided by the structure of the $\mathrm{C}^{4} \mathrm{~T}$, and incorporates relevant portions of the $\mathrm{C}^{4} \mathrm{~T}$, the RASAR-CCS is domain-specific. It was developed to examine USAR robot operator interactions with team members and to capture observable indicators of robot operator situational awareness.

The RASAR-CCS addresses the goals of capturing team process and situational awareness by coding each statement on four categories: 1) speaker-recipient dyad, 2) form or grammatical structure of the communication, 3) function or intent of the 
communication, and 4) content or topic of the communication. By examining dyad, form and content, one can determine which team members are interacting and what they are communicating about. Similarly, exploring elements of content and function allows one to examine indicators of operator situation awareness. The development of the RASARCCS is described below and the complete coding scheme is provided in Appendix A.

Speaker-recipient dyad codes were developed as a function of speaker-recipient pairs of individuals anticipated in a USAR environment. Nine dyads were constructed to describe conversations between individuals. Five dyad codes classify statements made by the operator to another person (or persons): operator-tether manager, operator- another team member, operator-researcher/robot technician, operator-group, or operator- other. The remaining four classify statements received by the operator from another person: tether manager-operator, another team member-operator, researcher/robot technicianoperator, or other- operator.

The primary dyads involve the operator and tether manager (the person manipulating the robot's tether during teleoperation), operator and researcher, or operator and another team member. The element operator-other is used when the operator addresses a specific person who does not match one of those roles. The operator-group dyad is used when the operator is addressing those present as a group, or when the operator's statements are not clearly addressed to a specific individual. Verbalizations between individuals which did not include the operator were not coded.

Similar to the $\mathrm{C}^{4} \mathrm{~T}$ taxonomy, the form category contains the elements: question, instruction, comment or answer. (RASAR-CCS uses the label instruction, while the $\mathrm{C}^{4} \mathrm{~T}$ 
uses the label command to describe statements dictating that some task or action take place). Statements not matching these categories are classified as undetermined.

To establish content and function codes a subset of operator statements (177 of the 272 total statements) were subjected to a Q-sort content analysis (Sachs, 2000). Two subject matter experts (SMEs) not involved in the study sorted operator statements on content - according to the topic being discussed, and on function - according to the high level purpose of the statement. Q-sort categories were reviewed and refined by two additional SMEs to ensure the elements reflected the domain of content and function. The Q-sort analysis based on content yielded seven elements representing the content category: 1- statements related to robot functions, parts, errors, or capabilities (State of the robot), 2- statements describing characteristics, conditions or events in the search environment (State of the environment), 3- statements reflecting associations between current observations and prior observations or knowledge (State of information gathered), 4- statements surrounding the robot's location, spatial orientation in the environment, or position (Robot situatedness), 5- indicators of direction of movement or route, (Navigation), 6- statements reflecting search task plans, procedures or decisions (Search Strategy), and finally 7- statements unrelated to the task (Off Task).

The first four content elements are necessary for building and maintaining SA in search operations, while the elements of navigation and search strategy require SA. Situation awareness is generated through information perceived (Level 1) and comprehended (Level 2) about the robot and environment. Since navigation and search 
strategy are elements that cannot be executed efficiently without SA, statements reflecting these are indicators of operator SA (Level 3).

Eight elements were identified from the Q-sort to represent the function category: 1- Asking for information from someone (Seek information), 2- Sharing observations about the robot or environment (Report), 3- Making a previous statement or observation more precise (Clarify), 4- Affirming a previous statement or observation (Confirm), 5Expressing doubt, disorientation, or loss of confidence in a state or observation (Convey uncertainty), 6- Projecting future goals or steps to goals (Plan), 7- Sharing information other than that described in report, either in response to a question, or offering unsolicited information (Provide information). For this study, the focus is on operator SA; hence an eighth element was included as a default for statements made by individuals other than the operator (Non-operator).

The function elements of reporting and providing information merit explanation, as they appear very similar. Reporting involves perception and comprehension of the state of the robot, robot situatedness, the environment or the state of information gathered. Any other information shared by an operator, in answer to a question or on his own, is classified as providing information (for example search strategy or navigation). Indicators of SA are captured in the function category primarily through the elements reporting and planning. When operator shares information (reports) based on the robot's eye view, one can infer the first two levels of SA, perception and comprehension, have taken place. The third SA level, planning and projection, is captured in the function category as the element "plan." 
The RASAR-CCS also obtains a global assessment of situational awareness, rated on a 5 -point Likert scale ( $1=$ low, $5=$ high). This observer rating is a subjective measure reached by consensus between the two raters. Video recordings of the operators manipulating the robot were used to code statements made by both the operators and surrounding personnel.

Two raters were trained to code videotapes using the RASAR-CCS. One rater (the author) was involved in data collection. The second rater, though not naïve, was not on site during data collection. Raters reviewed descriptions of the disaster drill and data collection procedures, and then reviewed definitions for all the codes. Coding guidelines were developed to reduce ambiguity and to enhance reliability. Behavioral examples selected from the videotapes were also reviewed. The majority of the training centered on coding statements together and reaching consensus. Training continued until both raters felt comfortable rating independently (approximately 8 hours).

A written transcript of each videotape was produced yielding a fixed number of statements to be coded (502 statements across the five operators). Using the Noldus Observer Video-Pro (Noldus, Trienes, Hendriksen, Jansen \& Jansen, 2000) observational coding software, raters coded 181 statements (36\%) in the transcripts along the four RASAR-CCS dimensions: dyad (speaker-recipient pair), form (grammatical structure of the communication), function (intent of the communication) and content (topic). Cohen's kappa (к) was computed to measure interrater agreement for each of the four coding dimensions: dyad, form, function, and content. Reliability analyses verified that raters agreed more than chance would predict, with Cohen's kappas of .72 for dyad, .78 for 
statement type, .64 for statement content and .72 for statement function. The remaining statements were coded by a single rater.

Codes for each of the 502 statements are used in data analyses. Frequencies, percentages and correlations of the RASAR-CCS categories and elements are generated to explore team process and communication: who's talking to whom (dyad), how (form), about what (content) and for what purpose (function). This is an exploratory study, in that I am looking for relationships that may have some bearing on effective human-robot interaction in the USAR domain. Therefore, all operator statement categories are included in analysis. Significant relationships emerged and are presented in each of the four categories. All correlations reported are significant at $\mathrm{p}<.05$ unless otherwise noted.

As mentioned previously, the RASAR-CSS obtains global assessments of situation awareness for each operator (5-point scale; 1=low, 5=high). These ratings were used to identify operators with high versus low situation awareness. Data from two operators receiving a rating of one were combined to form a low SA group and similarly, data from operators receiving a four or five were combined to form a high SA group (data from one operator receiving a three were not used in this analysis). Chi-square analyses are computed to determine differences in high and low SA operator statements relative to who the operator was communicating with (dyad), and the statement form, content and function. 


\section{CHAPTER 5}

\section{RESULTS}

This section presents findings related to situation awareness and team communication. Correlational analyses, chi-square analyses and statement category frequencies/percentages are presented in three major areas: SA, team process and communication, and the interaction of SA and team communication.

\section{Situation Awareness}

Operators had difficulty building or maintaining SA, and spent over half of their time trying to do so. As shown in Figure 4, 54\% of operator statements were related to gaining situation awareness at Levels 1 and 2 (state of robot \& robot situatedness- 38\%, state of environment- $13 \%$ and information gathered- 3\%) and considerably less time talking about factors requiring situation awareness (Level 3) to perform (navigation$21 \%$ and search strategy-16\%.)

Relationships between elements in the dimensions of content and function captured indicators of operator situation awareness (see Chapter 4 for a description of SA identifiers in the RASAR-CCS.) The correlation matrix of operator statement categories (Appendix B) revealed operator statements related to search strategy were strongly correlated with statements related to the state of the environment $(r=.94)$ and state of information gathered $(\mathrm{r}=.89)$. These two SA-related content areas were closely tied to each other $(\mathrm{r}=.91)$ as well, indicating the importance of linking what is being observed in the environment with what the operator already knows about the environment. 


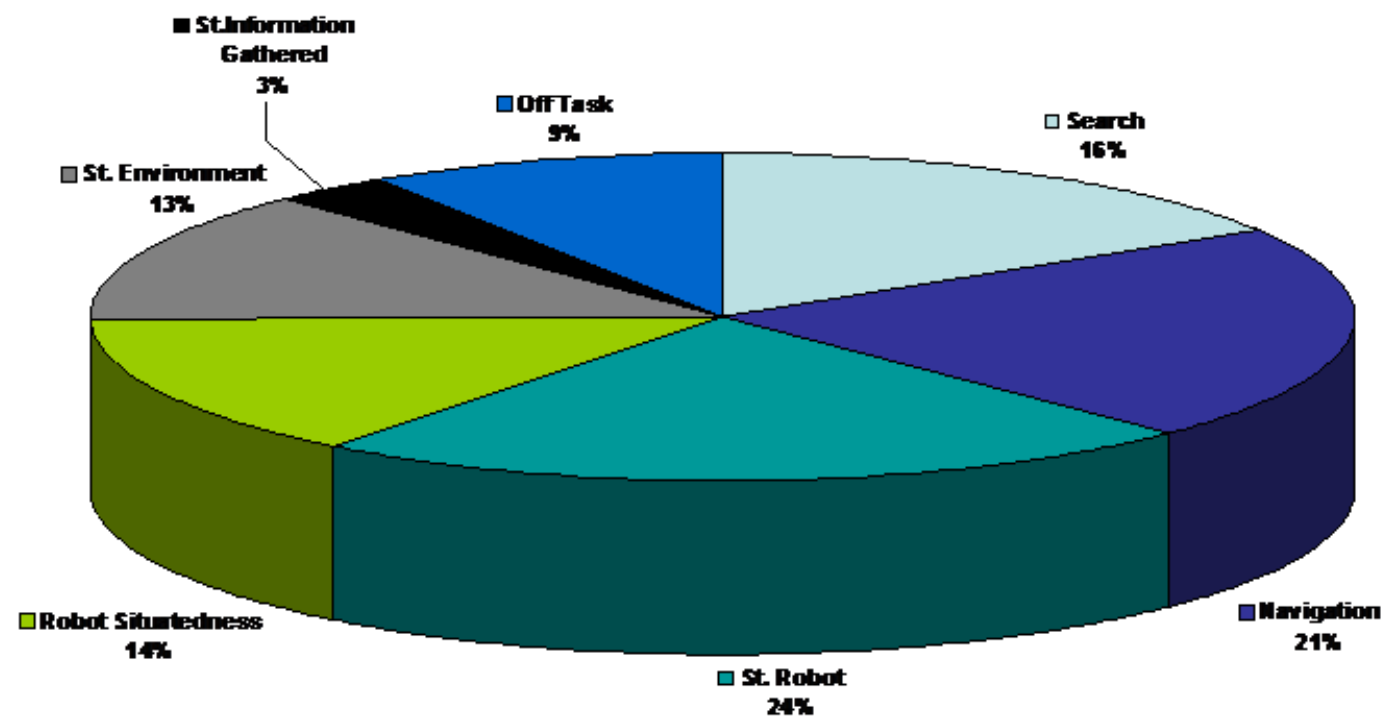

Figure 4. Percentages of operator statements by content.

Search strategy and planning are an intuitive fit because of the need to plan search activities, and indeed, search strategy statements correlated with statements coded as planning $(\mathrm{r}=.95)$ in the function category. However, the significant correlation of planning (a SA Level 3 indicator) with the state of the environment $(r=.98, p<.001)$ emphasizes the necessity of perception and comprehension in performing search operations. This is confirmed by another important relationship in this category between the two functions of plan and report $(r=.93$. The report element is used strictly when the operator is reporting on the state of the robot (including situatedness), environment or 
information gathered, all indicators of perception and comprehension (Levels I and II SA.) This clearly ties situation awareness to operator planning (SA Level 3) in HRI.

\section{Team Process and Communication}

Operators demonstrated team-based processes and communication techniques while using the robot in search operations, a finding supported by statement frequencies, percentages, and correlations between statement categories. Results are first presented for the 272 statements made by the operators to team members, since the study's focus is on the operator's mental model and situational awareness. Additional results examining operator \& team member statements are then presented. Table 2 provides frequency and percentage of occurrence of each descriptor by coding category. As seen in Table 1, operators spoke to other participants approximately 4 times per minute while teleoperating the robot $(\mathrm{M}=4.4, \mathrm{SD}=1.17 \mathrm{stmts} / \mathrm{min}$.

Almost $30 \%$ of the operators' statements were directed to team members directly connected to the task of navigating the robot in search of a victim (the tether manager, and the other team member; see Table 2.) Correlations (Appendix B) of operator-team member dyad with other variables in the coding system also depict the team-oriented nature of the robot search task. The operator's statements to his or her teammate correlated significantly with statements coded as instructions $(\mathrm{r}=.97, \mathrm{p}<.001$. $)$ The content categories related to operator-team member statements were state of information gathered and search strategy ( $r=.94$ for each), suggesting that in conversations with a 
teammate, the operator related what he was seeing to something he had seen before (or had prior knowledge of), and articulated search strategies.

Table 2. Operator statement category frequencies and percentages.

\begin{tabular}{llll}
\hline Category/Subcategory & Frequency & $\begin{array}{l}\text { Percentage of } \\
\text { Total by Category }\end{array}$ \\
\hline Dyad & & \\
& Operator-Tether Manager & 46 & 17 \\
& Operator-Researcher & 109 & 40 \\
& Operator-Team Member & 30 & 11 \\
& Operator-Other & 10 & 4 \\
Operator-Group & 77 & 28 \\
Form & & \\
& Question & 45 & 17 \\
Instruction & 8 & 3 \\
Answer & 99 & 36 \\
Comment & 120 & 44 \\
Content & & \\
& State of the Robot & 62 & 23 \\
$\quad$ State of the Environment & 36 & 13 \\
State of Information Gathered & 9 & 3 \\
Robot Situatedness & 38 & 14 \\
Search Strategy & 43 & 16 \\
Navigation & 57 & 21 \\
Off Task & 23 & 9 \\
(Missing content) & $(4)$ & 1 \\
Function & & \\
Seek Information & 29 & 11 \\
Report & 62 & 23 \\
Clarify & 11 & 4 \\
Confirm & 17 & 6 \\
Convey Uncertainty & 18 & 7 \\
Provide Information & 88 & 32 \\
Plan & 27 & 10 \\
( Missing function) & $(20)$ & 7 \\
\hline
\end{tabular}

Total number of statements $=272$ 
Correlations of operator statement form with content suggest operators' instructions were related to search strategy, the state of the environment and state of information gathered $(r=.99, .95, .92$ respectively.) In addition, instruction statements made by operators correlated significantly with statements coded as having a planning function $(\mathrm{r}=.94$.

Although the primary focus of this paper is on operator situation awareness and how operators talk to team members to facilitate SA, further analyses were conducted to explore information exchange between dyad members (see Figure 5). That is, operator statements to primary rescue team members (operator, tether manager, team member, and researcher - robot specialist) and from primary rescue team members to the operator were examined.

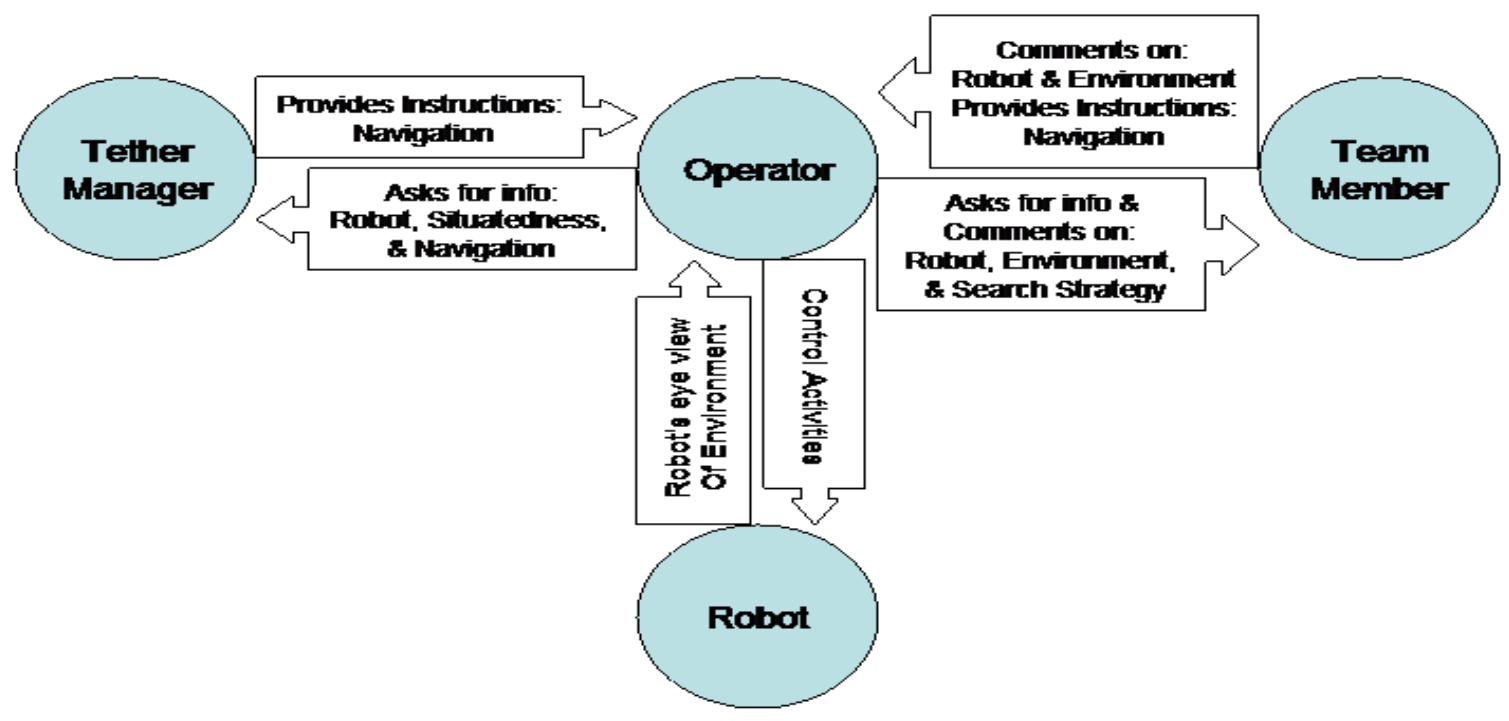

Figure 5. Team member interactions. 
Previously I examined the frequency of statements for each element within a category (e.g., 45 questions, or 62 statements regarding the state of the robot). In this analysis I examined, by dyad, the frequency of statements based on form, content and function combined to give an integrated picture of information exchange between rescue team members (e.g., the operator asked a question of the tether manager seeking information about the state of the robot).

Naturally, at this level of detail, the number of possible combinations ( 4 forms, 7 topics, and 7 functions) is formidable. Therefore, Table 3 presents only the three highest frequency statement types (including ties), broken down by speaker-recipient (i.e., operator - tether manager exchanges are presented as statements from the operator to the tether manager and by statements from the tether manager to the operator) for each dyad. Operators clearly had distinct expectations for information exchange between themselves and members of their team. Operators requested information from tether managers regarding the state of the robot $(9 \%)$, its situatedness $(6 \%)$ and navigation $(6 \%)$ and gave tether managers information and instructions ( $6 \%$ and $6 \%$, respectively) regarding the state of the robot. Conversely, operators asked team members for information on the robot (7\%), the environment (7\%), and search strategy (7\%), and offered information to team members regarding robot situatedness (7\%), the environment $(7 \%)$, and search strategy $(7 \%)$. 
Table 3. Dyad frequencies and percentages for tether managers and team members.

\begin{tabular}{|c|c|c|c|}
\hline Statement Type & $\begin{array}{l}\% \text { of Speakers } \\
\text { Statements }\end{array}$ & Statement Type & $\begin{array}{l}\% \text { of Speakers } \\
\text { Statements }\end{array}$ \\
\hline \multicolumn{4}{|c|}{ Operator - Tether Manager Exchanges $(n=83)$} \\
\hline Operator to Tether Manager $(n=47)$ & & $\begin{array}{l}\text { Tether Manager to } \\
\text { Operator }(n=36)\end{array}$ & \\
\hline $\begin{array}{l}\text { Question seeking information about } \\
\text { State of the Robot }\end{array}$ & $9 \%$ & $\begin{array}{l}\text { Instructions regarding } \\
\text { navigation }\end{array}$ & $22 \%$ \\
\hline $\begin{array}{l}\text { Question seeking information about } \\
\text { Robot Situatedness }\end{array}$ & $6 \%$ & $\begin{array}{l}\text { Comment on Robot } \\
\text { Situatedness }\end{array}$ & $11 \%$ \\
\hline $\begin{array}{l}\text { Question seeking information about } \\
\text { navigation }\end{array}$ & $6 \%$ & Comment on navigation & $11 \%$ \\
\hline $\begin{array}{l}\text { Instruction planning State of the } \\
\text { Robot }\end{array}$ & $6 \%$ & $\begin{array}{l}\text { Answer about State of } \\
\text { the Robot }\end{array}$ & $11 \%$ \\
\hline $\begin{array}{l}\text { Comment providing information on } \\
\text { the State of the Robot }\end{array}$ & $6 \%$ & & \\
\hline Answer reporting navigation & $6 \%$ & & \\
\hline Answer confirming navigation & $6 \%$ & & \\
\hline
\end{tabular}

Operator - Team Member Exchanges $(\mathrm{n}=76)$

Operator to Team Member $(\mathrm{n}=27)$

Team to Member

Operator $(n=49)$

Question seeking information about

State of the Robot

$7 \%$

Comment on State of the Robot

$14 \%$

Question seeking information about

St Environment

$7 \%$

Instruction, navigation

$12 \%$

Question seeking information about

search strategy

$7 \%$

Comment St Environ

$10 \%$

Comment St Environ report

$7 \%$

Comment Robot Situatedness report $\quad 7 \%$

Comment planning search strategy $\quad 7 \%$

Answer providing information about search strategy $7 \%$

\footnotetext{
*Percentages do not total $100 \%$ since only the three highest frequency statement types (including ties) are shown.
} 
Interaction of SA and Team Communication

Comparisons between operators rated as having high versus low SA on a global rating scale offer support for the influence of team behaviors on situation awareness. Chisquare results (Table 4) suggest operator communication with the tether manager $\left(\chi^{2}=\right.$ $16.2, \mathrm{p}<.001)$ and with other team members $\left(\chi^{2}=18.6, \mathrm{p}<.001\right)$ was related to high Situation Awareness. High SA operators also provided instructions more frequently then their low SA counterparts $\left(\chi^{2}=4.5, \mathrm{p}<.05\right.$. $)$

Furthermore, chi-square reveals that regardless of who they were speaking to, high SA operators made more statements than low SA operators about robot situatedness $\left(\chi^{2}=5.4, \mathrm{p}<.05\right)$ and about search strategy $\left(\chi^{2}=12.9, \mathrm{p}<.001\right)$ This suggests high SA operators had more knowledge of the robot's location and spatial orientation in the void space, and were more focused on goal-directed cues. It follows that the operator's situation awareness is a key factor in planning and executing search operations. Operators with low SA did not seem to have a plan as to how to search using the robot. Finally, high SA operators engaged in higher levels of reporting, i.e. they talked more to their teammates about SA-related factors in the search environment $\left(\chi^{2}=4.74\right.$, $\mathrm{p}<.05$.) And though not significant at the .05 level, the data suggests that low SA operators convey uncertainty more frequently than high SA operators $\left(\chi^{2}=3.55, \mathrm{p}=.06\right.$, $n s)$. 
Table 4. Chi-square results for high and low SA operator statements.

\begin{tabular}{|c|c|c|c|c|c|}
\hline & & $\begin{array}{l}\text { Low SA Operators } \\
\text { (frequency) }(\mathrm{N}=2)\end{array}$ & $\begin{array}{l}\text { High SA Operators } \\
\text { (frequency) }(\mathrm{N}=2)\end{array}$ & $\begin{array}{l}\text { Chi- } \\
\text { Square }\end{array}$ & p-value \\
\hline \multirow[t]{7}{*}{ Dyad } & Operator-Tether & 9 & 36 & 16.2 & $.000 * *$ \\
\hline & Manager & & & & \\
\hline & Operator- Team & 2 & 24 & 18.6 & $.000 * *$ \\
\hline & Member & & & & \\
\hline & Operator-Researcher & 56 & 52 & .15 & .70 \\
\hline & Operator-Other & 5 & 4 & .11 & .74 \\
\hline & Operator-Group & 42 & 32 & 1.35 & .25 \\
\hline \multirow[t]{4}{*}{ Form } & Question & 16 & 37 & 2.81 & .09 \\
\hline & Instruction & 1 & 7 & 4.5 & $.03 *$ \\
\hline & Answer & 46 & 49 & .09 & .76 \\
\hline & Comment & 51 & 65 & 1.69 & .19 \\
\hline \multirow[t]{10}{*}{ Topic } & State of the Robot & 30 & 30 & 0 & 1 \\
\hline & State of the & 14 & 20 & 1.06 & .30 \\
\hline & Environment & & & & \\
\hline & State of Information & 3 & 5 & .5 & .48 \\
\hline & Gathered & & & & \\
\hline & Robot Situatedness & 11 & 25 & 5.4 & $.02 *$ \\
\hline & Search Strategy & 9 & 32 & 12.9 & $.000 * *$ \\
\hline & Navigation & 32 & 24 & 1.14 & .29 \\
\hline & Off Task & 8 & 15 & 2.13 & .14 \\
\hline & (missing) & 0 & 4 & 4 & $.04 *$ \\
\hline \multirow[t]{8}{*}{ Function } & Seek Information & 10 & 17 & 1.81 & .17 \\
\hline & Reporting & 22 & 39 & 4.74 & $.03 *$ \\
\hline & Clarify & 5 & 6 & .09 & .76 \\
\hline & Confirm & 5 & 11 & 2.25 & .13 \\
\hline & Convey Uncertainty & 13 & 5 & 3.55 & .06 \\
\hline & Provide Information & 36 & 47 & 1.46 & .23 \\
\hline & Plan & 10 & 16 & 1.38 & .24 \\
\hline & (missing) & 13 & 7 & 1.8 & .18 \\
\hline
\end{tabular}




\section{CHAPTER 6}

\section{DISCUSSION}

Several aspects of the results merit further discussion below: the challenges in perception and situation awareness, the importance of team communication in developing mental models of the problem space and the support for findings of previous studies. Key Points

SA is critical to effective utilization of rescue robots in USAR, and operators had difficulty building and maintaining SA. The most important (and perhaps surprising) finding is that fully half of the operators' communication surrounds perceiving and interpreting (or trying to interpret) what is happening in the world, with the robot, and relating that information to what information is already known, with the remaining half related to planning search strategy, navigating and teleoperating. This finding is based on the fact that over half (54\%) of the statements made by the five operators were coded as content associated with situation awareness (Levels 1 and 2), an important aspect of human-robot interaction (Scholtz, 2003). It is also supported by the correlations of SArelated content categories with search strategy and planning. This contradicts traditional wisdom in robotics, which assumes navigation and mission tasks are conducted simultaneously. However, it confirms Sheridan's findings regarding the difficulties in teleproprioception and telekinesthesis during teleoperation (1992). 
This suggests one of the main challenges in achieving effective human-robot interaction is bridging the cognitive gaps between the two entities. The cognitive control tasks of navigating, searching, mapping, interpreting what is being seen on the video monitor, and making decisions about what to do with that information are overloading the operator. Training and experience may assist the USAR robot operator in forming a mental model of how "robot's eye" information is conveyed and then interpreted. What is clear, however, is that the information being received from the robot does not match the operator's current mental model. One explanation may be that the perceptual cues, e.g. the "keyhole effect" noted by Woods et al. (in press) are indeed challenging the operator, and that's where the cognitive deficits begin to appear. This difficulty in integrating the "robo-immersed view" with expectancies regarding the search process mirrors Casper's observations at WTC. In both cases fatigue certainly played a part; it seems likely, however, that lack of a cognitive model of how a robot "sees" is also a factor.

On an interesting note, videotapes recording the robot's eye view during the 5 operator deployments revealed an almost even split between the amounts of time operators spent actually moving the robot $(51 \%)$ as opposed to remaining stationary $(49 \%$.) The percentage of time the robot spent stationary is very similar to the percentage of statements devoted to SA Levels 1 and 2 (both are around 50\%). Correlational analyses of operator statements and robot movements are outside the scope of this study. However, it will be explored in future work.

The second key point is that it takes a team to use a robot in search operations, and not just physically: operators used team processes \& communication to compensate 
for the lack of SA-i.e., they tried to pool their perceptions to create a shared mental model, since they had difficulty coming up with one on their own. The significance of the operators' communication with teammates is important in terms of frequency, form, content and function. The team-oriented organizational structure of USAR stresses the interdependence between team members in getting the job done effectively. Operators discussed search strategy with their teammates using information about the environment, and relating it to what they already knew. Yet only $16 \%$ of their statements concerned the state of the environment, or related what they were seeing to known information, a telling percentage in light of the necessity of this information in search operations.

This suggests operators were attempting to develop a shared mental model with teammates in order to increase situation awareness. They also used this information to plan and devise search strategies. The report function used in the coding scheme was defined as "reporting about the state of the robot, environment or information gathered"-all SA-related topics. What is exciting is that reporting and planning were clearly related, i.e. operators were using what they were seeing through the robot's eye to form a mental model of the search space (and the robot's position in that space) in order to devise search strategies. Planning not only facilitates the building of shared mental models with teammates, it is also can result in improved team performance (Stout et al., 1999.) While it is surprising that navigation statements correlated only with statements function-coded as conveying uncertainty $(\mathrm{r}=.93)$, this may be artifactual, reflecting the lack of SA in two of the operators. 
The effective use of team processes and communication to compensate for the lack of SA suggests there is an interaction between SA and team communication. Operators with high SA talked to their teammates more about search strategies and robot situatedness, gave more instructions, and reported more on the state of the environment, robot, and information gathered. Talking about it helps create a mental model of what's happening.

This is important for future training and development in USAR, and also for robot system design. Confirming/disconfirming their interpretation of what was seen with another individual, collaborating with a teammate to project, plan and make decisions, and sharing information with other team members were not necessarily new strategies to the Task Force workers; the application of those strategies to working with a new technology, however, definitely was. This finding supports previous findings from an Air Force study of F-15C pilots (Bell \& Lyon, 2000) in which the most highly rated elements of SA were a) use of communication information and b) information integration from multiple sources. Other studies have noted the interrelation of team communication and situation awareness. Mosier \& Chidester (1991) found the number of situation awarenessrelated communications predicted team performance, and Bailey \& Willems (2002) reported air traffic controllers increased communications to maintain situation awareness under conditions of high workload.

Operator statements reflect specific expectations regarding the nature of each team member's roles (see Figure 5). The data suggests team members did not share the operator's role expectations. For example, although team members provided information 
on the robot and the environment, and provided instructions for navigation, they paid little attention to search strategy. In addition, tether managers provided information on the robot, and its situatedness; however, they mainly provided instructions regarding navigation. This suggests operators saw tether managers as a resource for obtaining information; whereas tether managers saw their role as providing assistance with navigation. While the operator saw team members as problem-holders, sharing pertinent information about the state of the robot and the environment and collaborating on search strategy, team members did not address operator needs regarding search strategy.

Lastly, quantitative analyses confirm previous research on HRI in search and rescue operations (Casper, 2002; Casper \& Murphy, 2003) which suggested that these tasks will be short and require two operators, not one. Time-on task with the robots was of short duration, with the average deployment drop lasting less than 15 minutes. (Timeon-task describes the time elapsed from the initial drop of the robot until the conclusion of the operator's run.) Four of the five operators utilized the robot for slightly under 15 minutes each $(\mathrm{M}=12.26 \mathrm{~min}, \mathrm{SD}=4.8 \mathrm{~min})$ in search operations. The fifth operator used the robot briefly during a rescue operation to try to see or get to the victim through a small void. When he saw that was not feasible, he terminated the run. These run times are similar to those of operators at the WTC (Casper, 2002). Actual drop times at the World Trade Center were even less, averaging 6-7 minutes. The ability to complete the search in a short time is a significant factor in the rescue worker's perception of the utility of a rescue robot. As new control tasks evolve utilizing the robots (e.g., carrying medical payloads to victims), operators may spend longer periods of time deploying them. 


\section{Conclusions}

This study reports on human-robot data from a disaster response training exercise conducted on a collapsed building site. While the number of operators video recorded is small, the data are rich and the findings lend support to prior research in the USAR domain and results from the WTC which indicated that perception, not navigation, is more significant than previously thought. The major findings of the study lead to the following conclusions:

- Cognitive augmentation in the form of intelligent perceptual assistance is needed. On average, the operator is actively engaged in the search task only $32 \%$ of the time. In addition, $54 \%$ of the operators' statements centered on perception and comprehension of the robot and environment. Finally, the amount of time the robot was stationary was close to $50 \%$. This suggests that it is extremely difficult for operators to establish situational awareness due to inherent perceptual challenges (the world is being perceived from an unnatural viewpoint, the lighting is uncontrolled, etc.) and lack of information in the user interface about the state of the robot (Is it upside down? What pose is it in?). This is consistent with the results of the previous studies of HRI in USAR (Casper \& Murphy, 2002; Casper \& Murphy, 2003).

- $\quad$ Robot-assisted technical search is a team task rather than an individual one. The human-robot ratio was never less than $2: 1$, in part, because physical robot operations require at a minimum, an operator and a tether manager. In addition, the search task itself demands information exchange among team members. More frequent 
communication with team members was related to higher ratings of operator SA (see Table 4). Furthermore, operator-team member communication was significantly related to statements involving search, instructions, and state of information gathered (Appendix B).

- $\quad$ Robot operators need a new cognitive mental model to filter and comprehend data provided by the robot, and to plan effective search strategies. More than half of operator statements were related to perception and comprehension of the robot and the environment perceived through the robot's eye view. Even so, the low frequency of statements regarding information needed to plan search (the state of the environment, $13 \%$; state of information gathered, $3 \%$ ) suggests operators had difficulty reconciling information obtained from the robot's eye view with their existing knowledge of the search environment.

- USAR technical search teams need a new shared mental model of the technical search task in order to coordinate activities effectively. Operators and their teammates did not have shared expectations regarding their roles in the search process (Figure 5). Operators saw tether managers as a resource for obtaining information about the robot in the environment along with navigation; whereas tether managers saw their role as primarily providing assistance with navigation. Similarly, the operator saw team members as problem-holders, sharing pertinent information about the state of the robot and the environment and collaborating on search strategy, however, team members did not address operator needs regarding search strategy (Figure 5). 
Though the results of this study are preliminary, and must be replicated, the findings give rise to numerous new questions:

- $\quad$ Is the amount of time spent building or maintaining situation awareness stable, or will it change as operators gain experience?

- Will cognitive augmentation shorten the time operators spend gaining SA?

- What perceptual cues are critical for gaining situation awareness in technical search operations?

- Will shared mental models of the robot, the environment and the search task improve operator performance in search operations?

Future research should examine these and other issues that emerge as USAR personnel acquire more experience working with increasingly sophisticated robotic technology. In particular, the use of visual information (the robot's eye view) as a resource has implications for new ways of conducting USAR operations. Sharing the robot information across various problem-holders in the organization (structural and medical specialists, incident commanders) could prove invaluable in reducing the time required to rescue disaster victims. The fact that these problem-holders may be physically remote suggests distributing robot information could reduce the effects of cognitive fatigue or localized noises and distractions that accompany search activities.

In addition, the RASAR Communication Coding Scheme generated to organize and examine human-robot interaction may provide insight into the nature of the manmachine relationship in USAR and in other robotic domains as robots continue to evolve and become a part of the workplace. Patterns of team process and communication may 
emerge through analysis that will be useful in training, e.g. robot operators may train in teams rather than individually in order to capitalize on the interaction between SA and team communication.

Currently, research is ongoing that applies the techniques described in this study to new data collected from 40 rescue professionals in two similar 24-hour high fidelity disaster response drills conducted in 2002-2003. The goals are to 1) identify operator and team mental models of robot-assisted search 2) pinpoint the perceptual cues that increase situation awareness and spur development of these models, and 3) continue to study the evolving processes of team communication and collaboration as robots are incorporated into USAR operations. It is expected that the study results will be useful for the larger case of anticipating (and facilitating) roles, tasks, and strategies that emerge when a new technology is introduced. 


\section{REFERENCES}

Arkin, R., Fujita, M., Takagi, T., and Hasegawa, R. (2003). An ethological and emotional basis for human-robot interaction. Robotics and Autonomous Systems, 42 (3-4), March 2003.

Bailey, L. \& Willems, B. (2002). The moderator effects of taskload on the interplay between en route intra-sector team communications, situation awareness, and mental workload. (DOT/FAA/AM-02/18). Department of Transportation, Federal Aviation Administration, Office of Aerospace Medicine, Washington, D.C.

Bell, H. \& Lyon, D. (2000). Using observer ratings to assess situation awareness. In M. Endsley \& D. Garland (Eds.), Situation Awareness Analysis and Measurement, (p. 129-146). Mahwah, NJ: Erlbaum.

Bluethmann, W., Ambrose, R., Diftler, M., Askew, S., Huber, E., Goza, M., Rehnmark, F., Lovchik, C., Magruder, D. (2003). Robonaut: A robot designed to work with humans in space. Autonomous Robots, 14 (2-3), 179-197.

Breazeal, C. (2000). Sociable machines: Expressive social exchange between humans and robots. Doctoral Dissertation, Department of Electrical Engineering and Computer Science, MIT.

Breazeal, C. (2003). Toward sociable robots. Robotics and Autonomous Systems, 42 (34), 167-175.

Brooks, R. (2002). Flesh and Machines: How Robots Will Change Us. New York: Pantheon. 
Casper, J. (2002). Human-robot interactions during the robot-assisted Urban Search and Rescue response at the World Trade Center. M.S. Thesis, Computer Science \& Engineering, University of South Florida.

Casper, J. \& Murphy, R. (2002). Workflow study on human-robot interaction in USAR. Proceedings of the International Conference on Robotics and Automation (ICRA) 2002.

Casper, J. \& Murphy, R. (2003). Human-robot interactions during the robot-assisted search and rescue response at the World Trade Center. IEEE Transactions on Systems, Man and Cybernetics, Part B, 33(3), 367 -385.

Draper, J., Pin, F., Rowe, J. and Jansen, J. (1999). Next generation munitions handler: Human-machine interface and preliminary performance evaluation. Proceedings of the $8^{\text {th }}$ International Topical Meeting on Robotics and Remote Systems, Pittsburgh, PA, Compact Disc.

Endsley, M. (1988). Design and evaluation for situation awareness enhancement. In Proceedings of the Human Factors Society $32^{\text {nd }}$ Annual Meeting, 1, 97-101. Santa Monica, CA: Human Factors Society.

Endsley, M. (2000). Theoretical underpinnings of situation awareness: A critical review.

In M. Endsley \& D. Garland (Eds.), Situation awareness: Analysis and Measurement (p.3-32). Mahwah, NJ: Erlbaum.

Fong, T., Thorpe, C. \& Baur, C. (2001). Collaboration, dialogue, and human-robot Interaction. Proceedings of the 10th International Symposium of Robotics Research, Lorne, Victoria, Australia. 
Jones, D. \& Endsley, M. (1996). Sources of situation awareness errors in aviation. Aviation, Space and Environmental Medicine, 67(6), 507-512.

Jones, H. \& Hinds, P. (2002). Extreme work groups: Using SWAT teams as a model for coordinating distributed robots. In Proceedings of the ACM 2002 Conference on Computer Supported Cooperative Work (CSCW 2002), 372-381, New Orleans LA.

Kawamura, K., Nilas, P., Muguruma, K., Adams, J. and Zhou, C. (2003). An agentbased architecture for an adaptive human-robot interface. Hawaii International Conference on System Sciences (HICSS-36), Big Island, Hawaii.

Khatib, O., Yokoi, K., Brock, O., Chang, K. \& Casal, A. (1999). Robots in human environments: Basic autonomous capabilities. International Journal of Robotics Research, 18(7), 684-696.

Kiesler, S. \& Goetz, J. (2002). Mental models of robotic assistants. In CHI 02 Extended Abstracts (Minneapolis, MN, April), ACM Press.

Kraut, R., Fussell, S. \& Siegel, J. (2003). Visual information as a conversational resource in collaborative physical tasks. Human-Computer Interaction, 18, 13-49.

Langle, T. \& Worn, H. (2001). Human-robot cooperation using multi-agent-systems. Journal of Intelligent \& Robotics Systems, 32 (2), 143-159.

Micire, M. (2002). Analysis of the robotic-assisted search and rescue response to the World Trade Center disaster. M.S. Thesis, Computer Science \& Engineering, University of South Florida. 
Mosier, K. \& Chidester, T. (1991). Situation assessment and situation awareness in a team setting. Proceedings of the $11^{\text {th }}$ Congress of the International Ergonomics Association, 798-800.

Murphy, R. (2000). Introduction to AI Robotics. Cambridge, MA: MIT Press.

Murphy, R. (2002). Rats, robots, and rescue. IEEE Intelligent Systems, 17, (5), 7 -9.

Murphy, R., \& Rogers, E. (2001). Human-robot interaction: Final Report for DARPA/NSF study on human-robot interaction. Retrieved June 5, 2002, from http://www.cse.calpoly.edu/ erogers/HRI/HRI-report-final.html.

Nakamura A., Ota J. and Arai T. (2002). Human-supervised multiple mobile robot system. IEEE Transactions on Robotics and Automation, 18 (5), 728-743.

Nicolescu, M. \& Mataric, M. (2001). Learning and interacting in human-robot domains. IEEE Transactions on Systems, Man \& Cybernetics-Part A: Systems and Humans, 31(5), 419-430.

Noldus, L., Trienes, R., Hendriksen, A., Jansen, H. \& Jansen, R. (2000). The Observer Video-Pro: new software for the collection, management, and presentation of timestructured data from videotapes and digital media files. Behavior Research Methods, Instruments \& Computers, 32, 197-206.

Peterson, L., Bailey, L., \& Willems, B. (2001). Controller-to-controller communication and coordination taxonomy $\left(C^{4} T\right)$. (DOT/FAA/AM-01/19). Department of Transportation, Federal Aviation Administration, Office of Aerospace Medicine, Washington, D.C. 
Prince, C. \& Salas. E. (2000). Team situation awareness, errors, and crew resource management: Research integration for training guidance. In M. Endsley \& D. Garland (Eds.), Situation Awareness Analysis and Measurement, (p. 325-347). Mahwah, NJ: Erlbaum.

Sachs, J. (2000). Using a small sample Q sort to identify item groups. Psychological Reports, 86, 1287-1294.

Scholtz, J. (2003). Theory and evaluation of human robot interactions. Hawaii International Conference on System Sciences (HICSS-36), Big Island, Hawaii. Severinson-Eklundh K, Green A, Huttenrauch H. (2003). Social and collaborative aspects of interaction with a service robot. Robotics and Autonomous Systems, 42 (3-4), 223234.

Sheridan, T. (1992). Telerobotics, automation, and human supervisory control. Cambridge, Massachusetts: MIT Press.

Sonnenwald, D. \& Pierce, L. (2000). Information behavior in dynamic group work contexts: Interwoven situational awareness, dense social networks and contested collaboration in command and control. Information Processing and Management, 36(2000), 461-479.

Stout, R., Cannon-Bowers, J., Salas, E. \& Milanovich, D. (1999). Planning, shared mental models, and coordinated performance: An empirical link is established. Human Factors, 41(1), 61-71.

Thrun, S. (1998). When robots meet people. IEEE Intelligent Systems, May/June 1998, 27-29. 
United States Federal Emergency Management Agency (1992). Urban Search \& Rescue Response Plan. United States.

Wickens, C. (1992). Engineering psychology and human performance. New York: Harper Collins.

Wilkes, D., Alford, A., Cambron, M., Rogers, T., Peters, R. \& Kawamura, K. (1999).

Designing for human-robot symbiosis. Industrial Robot 26(1), 47-58.

Woods, D., Tittle, J., Feil, M. \& Roesler, A. (in press). Envisioning human-robot coordination for future operation: A roboticist, cognitive engineer and problem holder confront demanding work settings. IEEE Transactions on Systems, Man \& Cybernetics: Part C: Special Issue on Human-Robot Interaction. 
APPENDICES 


\section{Appendix A: Robot Assisted Search and Rescue Communication Coding Scheme}

(RASAR-CCS)

\begin{tabular}{|c|c|c|}
\hline Category & Subcategories & Definitions \\
\hline \multirow[t]{17}{*}{ Sender/Recipient Dyad } & Operator-Tether & Operator: individual teleoperating the robot \\
\hline & Manager & \\
\hline & Tether Manager- & Tether manager: individual manipulating the tether \\
\hline & Operator & and assisting operator with robot \\
\hline & Team member- & Team member: one other than the tether manager \\
\hline & Operator & who is assisting the operator (usually by \\
\hline & & interpreting) \\
\hline & Operator- Team & \\
\hline & member & \\
\hline & Researcher-Operator & Researcher: individual acting as scientist or robot \\
\hline & & specialist \\
\hline & Operator-Researcher & \\
\hline & Other-Operator & Other -individual interacting with the operator who \\
\hline & & is not a tether manager, team member or researcher \\
\hline & Operator-Other & \\
\hline & Operator-Group & Group -set of individuals interacting with the \\
\hline & & operator \\
\hline Statement Form & Question & Request for information \\
\hline
\end{tabular}


Instruction

Comment

Answer

Content

Function
State of the robot

State of the

environment

State of information

gathered

Robot situatedness

Victim

Navigation

Search Strategy

Off task

Non-operator

Seek information

Report
Direction for task performance

General statement, initiated or responsive, that is not a question, instruction or answer

Response to a question or an instruction

Robot functions, parts, errors, capabilities, etc.

Characteristics, conditions or events in the search environment

Connections between current observation and prior observations or knowledge

Robot's location and spatial orientation in the environment; position

Pertaining to a victim or possible victim

Direction of movement or route

Search task plans, procedures or decisions

Unrelated or extraneous subject

Default for statements made by individuals other than the operator

Asking for information from someone

Sharing observations about the robot, environment, or victim 
Clarify

Confirm

Convey uncertainty

Plan

Provide information
Making a previous statement or observation more

precise

Affirming a previous statement or observation

Expressing doubt, disorientation, or loss of

confidence in a state or observation

Projecting future goals or steps to goals

Sharing information other than that described in

report, either in response to a question, or offering

unsolicited information 


\begin{tabular}{|c|c|c|c|c|c|c|c|c|c|c|c|c|c|c|c|c|c|c|c|c|c|c|c|}
\hline $\begin{array}{l}\text { Operator Statement } \\
\text { Categories }\end{array}$ & 1 & 2 & 3 & 4 & 5 & 6 & 7 & 8 & 9 & 10 & 11 & 12 & 13 & 14 & 15 & 16 & 17 & 18 & 19 & 20 & 21 & 22 & 23 \\
\hline \multicolumn{23}{|l|}{ Sender/Recipient Dyad } & \\
\hline 2. Operator-researcher & .03 & 1.00 & & & & & & & & & & & & & & & & & & & & & \\
\hline 3. Operator-team mbr & -.26 & .35 & 1.00 & & & & & & & & & & & & & & & & & & & & \\
\hline 4. Operator-other & .02 & .04 & .20 & 1.00 & & & & & & & & & & & & & & & & & & & \\
\hline 5. Operator-group & .19 & .68 & -.03 & .63 & 1.00 & & & & & & & & & & & & & & & & & & \\
\hline 6. Question & .14 & .82 & .59 & -.28 & .23 & 1.00 & & & & & & & & & & & & & & & & & \\
\hline \multicolumn{24}{|l|}{ Statement Form } \\
\hline 7. Instruction & -.15 & .43 & $.97^{* *}$ & .41 & .22 & .57 & 1.00 & & & & & & & & & & & & & & & & \\
\hline 8. Answer & .31 & $.89 *$ & .08 & -.23 & .55 & .83 & .15 & 1.00 & & & & & & & & & & & & & & & \\
\hline 9. Comment & .45 & .41 & .28 & .80 & .80 & .22 & .52 & .30 & 1.00 & & & & & & & & & & & & & & \\
\hline \multicolumn{24}{|l|}{ Content } \\
\hline 10. State of the Robot & .65 & .58 & -.38 & -.15 & .57 & .45 & -.26 & .84 & .35 & 1.00 & & & & & & & & & & & & & \\
\hline $\begin{array}{l}\text { 11. State of } \\
\text { Environment }\end{array}$ & -.22 & .62 & .87 & .50 & .46 & .59 & $.95^{*}$ & .30 & .61 & -.12 & 1.00 & & & & & & & & & & & & \\
\hline 12. State of Information & -.30 & .63 & $.94 *$ & .10 & .16 & .77 & $.92 *$ & .37 & .28 & -.15 & $.91 *$ & 1.00 & & & & & & & & & & & \\
\hline 13. Robot Situatedness & .69 & .53 & .42 & .00 & .31 & .77 & .49 & .67 & .57 & .58 & .44 & .47 & 1.00 & & & & & & & & & & \\
\hline 14. Search & -.04 & .44 & $.94 *$ & .44 & .26 & .58 & $.99 * *$ & .19 & .60 & -.18 & $.94 *$ & $.89 *$ & .57 & 1.00 & & & & & & & & & \\
\hline 15. Navigation & .56 & .30 & -.45 & .53 & .84 & -.08 & -.20 & .39 & .71 & .71 & -.01 & -.34 & .28 & -.12 & 1.00 & & & & & & & & \\
\hline 16. Off Task & -.04 & .76 & -.27 & -.37 & .46 & .51 & -.24 & .84 & -.07 & .72 & -.02 & .08 & .16 & -.25 & .31 & 1.00 & & & & & & & \\
\hline \multicolumn{24}{|l|}{ Function } \\
\hline 17. Seek Information & .28 & .75 & .46 & -.39 & .17 & $.98 * *$ & .44 & .85 & .16 & .54 & .43 & .65 & .81 & .46 & -.05 & .53 & 1.00 & & & & & & \\
\hline 18. Report & .35 & .68 & .66 & .43 & .60 & .71 & .80 & .57 & .82 & .35 & .83 & .72 & .84 & .85 & .34 & .09 & .65 & 1.00 & & & & & \\
\hline 19. Clarify & .28 & .65 & -.09 & -.66 & .13 & .74 & -.13 & $.88^{*}$ & -.15 & .76 & -.06 & .19 & .52 & -.11 & .09 & .83 & .82 & .22 & 1.00 & & & & \\
\hline 20. Confirm & .72 & .44 & .06 & -.45 & .09 & .72 & .06 & .76 & .17 & .75 & .01 & .18 & .86 & .13 & .20 & .41 & .84 & .48 & .81 & 1.00 & & & \\
\hline 21. Convey uncertainty & .26 & .17 & -.49 & .67 & .81 & -.34 & -.25 & .13 & .62 & .44 & -.03 & -.41 & -.07 & -.19 & $.93 *$ & .21 & -.36 & .14 & -.19 & -.18 & 1.00 & & \\
\hline 22. Provide Information & .52 & .49 & .31 & .70 & .79 & .35 & .53 & .42 & $.99 *$ & .44 & .61 & .33 & .69 & .62 & .70 & .01 & .30 & .87 & -.01 & .32 & .56 & 1.00 & \\
\hline 23. Plan & -.01 & .65 & .83 & .52 & .53 & .64 & $.94 *$ & .39 & .73 & .04 & $\begin{array}{l}.98^{*} \\
*\end{array}$ & .86 & .60 & $.95^{*}$ & .13 & .00 & .51 & $.93 *$ & .02 & .18 & .04 & .75 & 1.00 \\
\hline
\end{tabular}

